\title{
Insect juvenile hormone: from "status quo" to high society
}

K. Hartfelder

\section{Correspondence}

K. Hartfelder

Departamento de Biologia

FFCLRP, USP

Av. Bandeirantes, 3900

14040-901 Ribeirão Preto, SP

Brasil

E-mail: khartfel@ rgm.fmrp.usp.br

Presented at the XIII Annual M eeting of the Federação de Sociedades de Biologia Experimental, Caxambu, MG, Brasil, August 26-29, 1998.

Research supported in part by a DFG grant (Ha 1625/3-1) and a CAPES-DAAD fellowship.

Publication supported by FAPESP.

Received July 7, 1999

Accepted November 19, 1999
Departamento de Biologia, Faculdade de Filosofia,

Ciências e Letras de Ribeirão Preto, U niversidade de São Paulo, Ribeirão Preto, SP, Brasil

\section{Abstract}

Juvenile hormone $(\mathrm{JH})$ exerts pleiotropic functions during insect life cycles. The regulation of JH biosynthesis by neuropeptides and biogenic amines, as well as the transport of $\mathrm{JH}$ by specific binding proteins is now well understood. In contrast, comprehending its mode of action on target organs is still hampered by the difficulties in isolating specific receptors. In concert with ecdysteroids, JH orchestrates molting and metamorphosis, and its modulatory function in molting processes has gained it the attribute "status quo" hormone. Whereas the metamorphic role of $\mathrm{JH}$ appears to have been widely conserved, its role in reproduction has been subject to many modifications. In many species, JH stimulates vitellogenin synthesis and uptake. In mosquitoes, however, this function has been transferred to ecdysteroids, and JH primes the ecdysteroid response of developing follicles. As reproduction includes a variety of specific behaviors, including migration and diapause, $\mathrm{JH}$ has come to function as a master regulator in insect reproduction. The peak of pleiotropy was definitely reached in insects exhibiting facultative polymorphisms. In wingdimorphic crickets, differential activation of $\mathrm{JH}$ esterase determines wing length. The evolution of sociality in Isoptera and Hymenoptera has also extensively relied on $\mathrm{JH}$. In primitively social wasps and bumble bees, $\mathrm{JH}$ integrates dominance position with reproductive status. In highly social insects, such as the honey bee, JH has lost its gonadotropic role and now regulates division of labor in the worker caste. Its metamorphic role has been extensively explored in the morphological differentiation of queens and workers, and in the generation of worker polymorphism, such as observed in ants.
Key words

- Juvenile hormone

- Corpora allata

- M etamorphosis

- Insect reproduction

- Polymorphism

- Honey bee

\section{Introduction}

Few hormones have puzzled and fascinated entomologists more than juvenile hormone $(\mathrm{JH})$. This is obviously due to the hormone's pleiotropic functions, from a) orchestrating metamorphosis in concert with the molt-inducing ecdysteroid hormones, $b$ ) regulating female fertility by stimulating vitellogenin synthesis in the fat body and its uptake by the growing oocytes, up to the c) generation of sophisticated polymorphisms in aphids and social insects. In this sense, JH is clearly a pleiotropic master hormone of insects which governs most aspects of their integration with the ecosystem and affects 
decisive life history parameters during their entire life cycles. JH has been considered to be an exclusive insect hormone and thus has attracted much attention also in plant and grain protection-oriented research. Recent studies, however, provide evidence that marine annelids can detect compounds with juvenoid activity and can use these as metamorphosis signals (1). In crustaceans, the JH precursor methyl farnesoate, which is produced in the mandibular organ, assumes many roles attributed to $\mathrm{JH}$ in insects (2). If comparative endocrinology and neuroendocrinology is understood as being more than just the compilation of endocrine physiology of non-mammalian animals, i.e., of approximately $99 \%$ of the animal kingdom, then a closer look at such master regulators should contribute to our understanding of the evolution of hormones and of their receptors. Furthermore, we may come to a broader comprehension of how each class of animals has dealt during its evolution with such basic problems as homeostasis, as well as coordinated development and reproduction in variable environmental conditions.

The purpose of the present review is not to go into all the details and intricacies of $\mathrm{JH}$ function(s). Excellent recent reviews $(3,4)$ have covered this field extensively. Instead, the intention of this review is to present, as briefly as possible, the basic paradigms of this hormone's function and physiology in insects, and to concentrate more on its wide-ranging ecological implications, i.e., to show how profoundly it can shape and even modify life histories. The most dramatic changes in life histories can be encountered in social insects, where most individuals of a colony bestow most of their reproductive potential upon a dominant queen (in Hymenoptera) or a royal pair (in termites). Emerging views from studies on social insects now clearly indicate that JH also is deeply entrenched in practically all aspects of social life, affecting the generation not only of different morphs, but also of neural and resulting behavioral plasticity.

\section{Juvenile hormones: chemistry, biosynthesis, and modes of action}

By grafting different life stages of the blood-sucking bug, Rhodnius prolixus, Wigglesworth (see Refs. 3,4) discovered in 1936 that JH has two major roles in an insect's physiology and life history, namely to prevent metamorphosis and to regulate reproduction. Its function to prevent the precocious metamorphosis of an insect larva into an adult when passing through frequent molts, gained it the title "status quo" hormone. The small quantities of JH present either in the site of synthesis, the corpora allata $(\mathrm{CA})$ in the retrocerebral endocrine complex, or circulating in insect hemolymph, however, considerably delayed the elucidation of the chemical structure of $\mathrm{JH}$.

The serendipitious discovery of a copious source of $\mathrm{JH}$ in abdomens of male saturniid silkmoths, Hyalophora cecropia made possible the chemical identification of $\mathrm{JH}$ (then designated as JH I) as a sesquiterpenoid epoxide methyl ester. Subsequently, a small number of closely related compounds was isolated and identified (for structures, see Ref. 3). JH I and occasionally also JH II are principally found in lepidopterans, whereas the JH homolog detected throughout all insect orders is JH III, the trimethyl homolog. $\mathrm{JH}$ 0, the triethyl homolog, has only been found in lepidopteran embryos. JH acids, the non-methylated derivatives of $\mathrm{JH}$, also constitute a relevant fraction of $\mathrm{JH}$ compounds circulating in hemolymph of moths and may have hormonal functions that cannot be performed by JH itself. The cyclorraphan dipterans and some hemipterans possess a special type of $\mathrm{JH}$, namely a bisepoxide version of JH III. A new class of juvenile hormones, the hydroxy juvenile hormones, have recently been identified as biosynthesis products of locust corpora allata (5), apparently as byproducts of JH III synthesis.

The practically exclusive sites of JH synthesis are the CA, a distinct pair of glands in 
the retrocerebral complex (Figure 1) attached to the brain via two or three pairs of nerves. De novo synthesis of $\mathrm{JH}$ starts from acetyl CoA and/or propionyl CoA subunits and follows the mevalonate pathway to farnesoic acid (for a review of JH biosynthesis, see Ref. 6). The last two steps are the methylester formation, leading to methyl farnesoate, and the introduction of an epoxide group in position 10,11 of the carbon skeleton. Tobe and Pratt (7) took advantage of the exclusive utilization of S-adenosyl-methionine as donor of the methyl group in the esterification step in JH biosynthesis and developed a highly sensitive radiochemical in vitro assay for the determination of rates of JH synthesis. This assay was crucial to the elucidation of regulatory pathways and for the identification of neurohormones stimulating or inhibiting CA activity.

An inhibitory regulation of the CA via the descending nerves has been proposed several decades ago, but the principal players, the allatostatic neuropeptides, have only been identified ten years ago in the viviparous cockroach, Diploptera punctata. The Diploptera allatostatins are a family of amidated peptides with a conserved C-terminus (FGLamide), which differ from known peptides in other organisms. These FGLamides are a widespread class of peptides in insects and include the allatostatins of cockroaches and crickets, as well as structurally related peptides of locusts and blowflies. Regulation of JH synthesis appears to be only one of the many functions of these peptides. As expected, allatostatin immunoreactive neurons could be detected in lateral neurosecretory cells innervating the $\mathrm{CA}$ of D. punctata (8), but were also found in other regions throughout the central nervous system, including thoracic motoneurons and nerves innervating the gut. In the tobacco hornworm, Manduca sexta, they appear to have neuromodulatory and myotropic functions, but do not exhibit allatoregulatory activity. The authentic allatostatin of Manduca sexta, however, does not resemble the
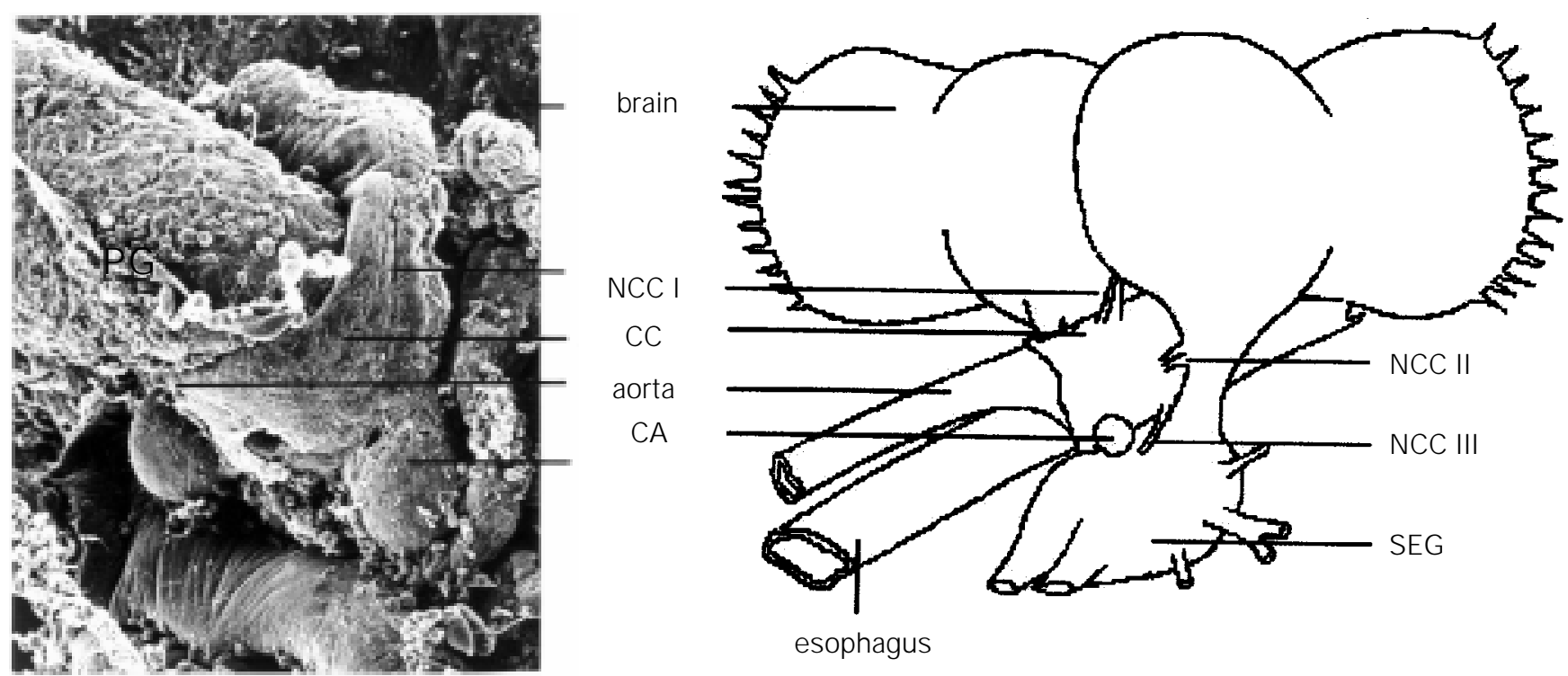

Figure 1 - The retrocerebral endocrine complex of insects as exemplified by the honey bee. SEM micrograph (left) of the corpora cardiaca and the juvenile hormone-producing corpora allata. The NCC is seen to cross the corpora cardiaca which are tightly connected to the aorta on top of the esophagus. Schematic drawing (right) of the brain and associated endocrine system of a honey bee pupa. Three pairs of nerves descend from different brain regions forming the brain-corpora cardiaca-corpora allata neuroendocrine axis. CA, Corpora allata; CC, corpora cardiaca; NCC I-III, nervi corporis cardiaci I-III, respectively; PG, string of prothoracic gland cells; SEG, subesophageal ganglion. 
Diploptera allatostatins. The only peptide stimulating JH synthesis has been identified in M. sexta (9). It stimulates JH synthesis in CA of adults only, and appears to be restricted to lepidopterans in its activity.

The mode of action of allatostatins on CA cells is principally mediated via calcium signalling involving protein kinase $\mathrm{C}$ (10). The enzymes affected by allatostatins appear to be situated at both ends of the biosynthesis pathway. Sutherland and Feyereisen (11) propose an inhibitory action on the transfer of the initial $\mathrm{C}_{2}$ units from mitochondria to the cytoplasm, but, interestingly, not on the much speculated HMG-CoA reductase, which is a rate-limiting enzyme in vertebrate steroid synthesis. In some insects, such as $D$. punctata, allatostatins also affect the terminal steps of JH biosynthesis in the CA (12). In addition to these specific neuropeptides, some biogenic amines, octopamine, serotonin, and dopamine, also turned out to be potent modulators of CA activity, apparently being coupled to cAMP as second messenger system $(13,14)$. Their activity, however, strongly varies between species, and even between different developmental stages in the same species.

Being highly lipophilic, the insect JHs are transported from their site of synthesis to target tissues via specific high affinity binding proteins that aid their transport in the hemolymph. Most insects use lipophorins or hexameric proteins (Orthoptera) as highmolecular-weight high-affinity JH-transport proteins, except for the lepidopterans which have specific low-molecular-weight JH carriers (15). Detailed simultaneous analyses of $\mathrm{JH}$ titer and of JH-binding proteins in hemolymph revealed that practically all $\mathrm{JH}$ is bound to these carriers, which appear to be always present in excess. In conjunction with their transport role, these proteins also protect JH from degradation by general esterases. Metabolic inactivation of JH occurs by two major pathways, by specific JH esterases in the hemolymph and by tissue bound epoxide hydrolases. JH esterases clear $\mathrm{JH}$ from the hemolymph during critical developmental phases (16), apparently acting in synergism with JH-binding proteins.

Crucial to the isolation and identification of these JH-binding and -metabolizing proteins was the synthesis of highly specific $\mathrm{JH}$ analogs for photoaffinity labeling (17). This strategy was also employed in the search for the most interesting of all JH-binding proteins, the JH receptor(s). Based on the chemical nature of JH and on analogy to ecdysteroids, most research concentrated on nuclear receptors. The most promising candidate, however, a $29-\mathrm{kDa}$ protein isolated from larval epidermis of M. sexta, has since turned out to be artifactual. Putative JH receptors isolated from the cockroach Leucophaea maderae and from Locusta migratoria also appear to be cellular JH-binding proteins (18), possibly involved in the transport of this hydrophobic ligand to its actual receptor. These proteins are present far in excess of the $10^{4}$ copies/cell estimated for steroid and thyroid hormone receptors. Due to the structural similarity of JH to retinoids, homologs of RXR have been proposed as possible candidates for a JH receptor. The RXR homolog of insects, however, turned out to be the product of the ultraspiracle gene, which is the heterodimer partner of the ecdysone receptor.

In addition to a nuclear $\mathrm{JH}$ receptor, the action of $\mathrm{JH}$ on a $\mathrm{Na}^{+} / \mathrm{K}^{+}$-ATPase in the ovary of Locusta migratoria has stimulated research on a JH-binding protein in the membrane of the follicular epithelium (19), which has been proposed as a putative membrane receptor for JH. So, the somewhat enigmatic situation is whether the elusive insect-JH receptor not only exists as different isoforms, just as the ecdysone receptor, but possibly also as distinct nuclear and transmembrane moieties. Even more than in the search for the ecdysone receptor most attempts to identify the JH receptor have been plagued by the propensity of $\mathrm{JH}$ to bind nonspecifically to 
many substrates and by the apparent abundance and variety of specific JH-binding proteins. Taking a genetic approach, such as the methoprene selection screen in Drosophila, has led to the identification of the methoprene-tolerant $(\mathrm{Met}$ ) mutation. Cloning and sequencing of the Met(+)-gene showed homology to the basic helix-loophelix-PAS family of transcription factors, implicating Met protein in a gene regulatory function of JH (20). Met(+) could now be linked to the ecdysone-inducible Broad-Complex transcription factors (21), suggesting that it is an early downstream element in the $\mathrm{JH}$ response cascade. Looking for gene products that interact with $\operatorname{Met}(+)$ may turn out to be an interesting alternative in the search strategies for the $\mathrm{JH}$ receptor.

\section{Juvenile hormone: the "status quo" factor in molting and metamorphosis}

During larval development, the presence of $\mathrm{JH}$ in the hemolymph prevents an insect from precociously turning into an adult, thus explaining the nomenclature "juvenile hormone" and "status quo" factor. Early models proposed a gradual decline of JH titers associated with cyclic surges of ecdysone, the molt-inducing hormone. Actual quantifications of $\mathrm{JH}$ and ecdysteroid titers, however, revealed a much more complicated and intricate regulation of the premetamorphic and metamorphic molts, particularly in holometabolous insects which have to pass through a complete reorganization of body structure during the pupal stage. Meticulous titer analyses, together with surgical experiments and application of synthetic hormones, were carried out mainly on the tobacco hornworm, Manduca sexta, making this moth the preferred model system for studies on insect metamorphosis. In each larval stage, a JHsensitive period was detected which usually occurs concomitantly with the molt-inducing ecdysone peak. In the last (fifth) larval instar of M. sexta, two such JH-sensitive periods could be found, together with marked differences in hormone titer profiles when compared to the earlier instars (for review, see Ref. 3). In the fifth instar, the JH titer declines when the larva has reached a critical weight. This decline stimulates the lateral neurosecretory cells of the brain to release prothoracicotropic hormone (PTTH), which in turn elicits ecdysone synthesis and release from the prothoracic glands. Thus, for the first time in the life cycle, a surge of ecdysone occurs in the absence of JH. This surge of ecdysone has been termed the "commitment" peak since it has a profound effect on the larval epidermis, essentially erasing the program of larval cuticle synthesis. Two days later, another surge of PTTH, now accompanied by a high $\mathrm{JH}$ titer, results in a much higher ecdysone peak, which elicits the next molt. The presence of JH during the $\mathrm{JH}$-sensitive period early in this second ecdysone peak ensures that the epidermis synthesizes a pupal cuticle and not precociously an adult cuticle. Thus, JH preserves the "status quo" in terms of the program triggered by the ecdysteroid peak, and it does so, apparently universally, in all insects. The only difference between hemimetabolous and holometabolous insects seems to lie in the complexity of interactions between the moltinducing ecdysteroids, in particular 20hydroxyecdysone $(20 \mathrm{E})$, and the molt-directing $\mathrm{JH}$.

As stated above, $\mathrm{JH}$ is a pleiotropic master regulator acting both at the central level in the neuroendocrine axis and on peripheral target tissues like the epidermis and fat body. At the central level, JH inhibits the release of the ecdysiotropic brain hormone PTTH early in the fifth larval instar of $M$. sexta, but then two days later it looses this repressor effect. It is not yet clear how JH exerts, and especially reverses, its effect on the PTTH-producing lateral neurosecretory cells. Apparently, the actual regulatory pathways within the neuroendocrine axis are not only complex and distinct within different life cycle 
stages of a species, but may also be quite different between insect orders. Whereas in lepidopterans $\mathrm{JH}$ affects prothoracic gland activity primarily through the PTTH pathway (22), incubation of isolated prothoracic glands of honey bee larvae in the presence of the $\mathrm{JH}$ analog methoprene directly stimulated ecdysteroid production in vitro (23).

In-depth studies on the premetamorphic and metamorphic effects of JH on peripheral target tissues have mainly focussed on the larval epidermis and prolegs of $M$. sexta. The model of coordinated switches from a larval to a pupal and then to an imaginal program of cuticle synthesis, proposed from macroscopic analyses of cuticle types produced during the molting cycles, however, has not yet been validated at the molecular level. Temporal expression patterns of individual genes coding for different larval cuticle proteins of $M$. sexta, as well as for pigmentation factors (larval insecticyanin and the melanization-triggering enzyme dopadecarboxylase) were studied extensively (see Ref. 3). These genes exhibit many apparently idiosyncratic temporal expression patterns, suggesting that $\mathrm{JH}$ and probably even more directly ecdysteroids interact or compete for binding sites in the upstream control region of the respective genes. A putative model for the interaction of $20 \mathrm{E}$ and $\mathrm{JH}$ based on studies of dopadecarboxylase gene expression proposes that $\mathrm{JH}$ in conjunction with $20 \mathrm{E}$ induces a long-lived positive transcription factor $\mathrm{A}$, whereas $20 \mathrm{E}$ alone induces a short-lived negative-effect factor (3). In this scenario, degradation of the 20Einduced factor is expected to result in a burst of dopadecarboxylase expression which should last until the $\mathrm{JH} / 20 \mathrm{E}$-coregulated factor is also degraded.

Whereas most of these studies on $\mathrm{JH}$ regulated gene expression were looking at target genes at the end of a JH-induced response cascade, a more recent line of research is trying to decipher the putative elements within such a cascade. Just as the
Broad-Complex mentioned above, the expression pattern of a M. sexta homolog of the 20E-induced transcription factor E75A of Drosophila melanogaster exhibited responsiveness also to JH (24). Drosophila-E75 encodes an orphan member of the nuclear hormone receptor superfamily. In Manduca, the rapid, transient induction of $E 75 \mathrm{mRNA}$ by $20 \mathrm{E}$ turned out to be much attenuated in epidermis of fourth-instar larvae, which typically have a high endogenous JH titer. These findings show for the first time that $\mathrm{JH}$ plays a role in 20E-induced early gene expression and suggest that the higher levels of E75A may be required for maintenance of larval commitment of this epidermis. It is not yet clear whether $\mathrm{JH}$ acts directly on the E75 gene to influence its transcription rate, or whether it affects the stability of $E 75$ mRNA.

Evidence for a modulatory role of $\mathrm{JH}$ in the expression of 20E-regulated genes comes from studies on larval storage proteins synthesized in the fat body of the cabbage looper, Trichoplusia ni, strongly supporting the idea that $\mathrm{JH}$ affects both transcription rates and mRNA stability. With the exception of arylphorin, most of the larval storage proteins of $T$. ni turned out to be regulated (suppressed) by $\mathrm{JH}$ at the transcriptional level. DNase-I hypersensitive site mapping suggested conformational changes in a region 50-100 bp 5' upstream of the TATA box (25). Nuclear run-on assays presented evidence that poly(A) tail length of storage protein mRNAs was modulated by exposure to $\mathrm{JH}$. These storage proteins belong to the class of hexamerins which are synthesized by the larval fat body. They serve as reserves for the reconstruction processes occurring during the pupal phase. Additionally, they may serve as metabolic reserves for insects that are not feeding in the adult stages.

\section{The gonadotropic roles of juvenile hormone}

$\mathrm{JH}$ acts on so many aspects of insect 
reproduction that it can justly be called a master regulator of the "female reproduction syndrome". In addition to its central role in oogenesis, JH affects dispersal and flight activity, calling behavior, postcopulatory changes in female behavior, and oviposition behavior. The diversity of life history strategies in insects and a myriad of adaptations that enabled them to colonize practically every terrestrial habitat, however, generated a plethora of twists and turns that preclude the proposal of a unifying $\mathrm{JH}$ hypothesis for hormonal regulation of insect reproduction. Quite different from the more conserved role of $\mathrm{JH}$ as a modulator of ecdysteroid action in larval-pupal development, the roles of $\mathrm{JH}$ in adult insects are, at first sight, rather confusing. However, once the roles and implications of $\mathrm{JH}$ action in the different aspects of the reproduction syndrome are carefully evaluated with respect to timing of reproduction and trade-offs between different reproductive strategies, some general principles may emerge. In many aspects, the role of $\mathrm{JH}$ in insect reproduction - schematically compiled in Figure 2 - could, therefore, be considered as that of a conserved integrator which provides a platform for flexibility in life history strategies.

\section{Vitellogenesis}

The gonadotropic role of JH was established by ingenuous transplantation and ligation experiments carried out by Wigglesworth on females and males of the bloodsucking bug, Rhodnius prolixus (see Ref. 4). Vitellogenesis in females and synthetic activity of the male accessory gland were blocked by ligation and could be reinstalled in this species by transfer of active CA. Due to their larger size and ease of rearing, most subsequent experiments on vitellogenin synthesis by the female fat body and uptake of this protein by the growing oocytes were performed on cockroaches and locusts as model systems. Insect vitellogenins are members of a large family of lipid-binding proteins that exhibit conserved domains between protostome and deuterostome phyla (26). The titer of these proteins secreted by the fat body of adult female insects can account for up to $50 \%$ of their total hemolymph proteins. Particularly in long-lived adult insects with distinct reproductive cycles, synthesis of this major hemolymph protein must be correlated with oocyte development. The regulation of vitellogenin synthesis, its dependence on $\mathrm{JH}$, and the mode of action of $\mathrm{JH}$ in vitellogenin gene expression has been, and continues to be, most extensively studied in the migratory locust, Locusta migratoria, and in the viviparous cockroach Leucophaea maderae (for review, see Ref. 4). Vitellogenin transcription rates and $\mathrm{JH}$ III titers are fairly well correlated throughout

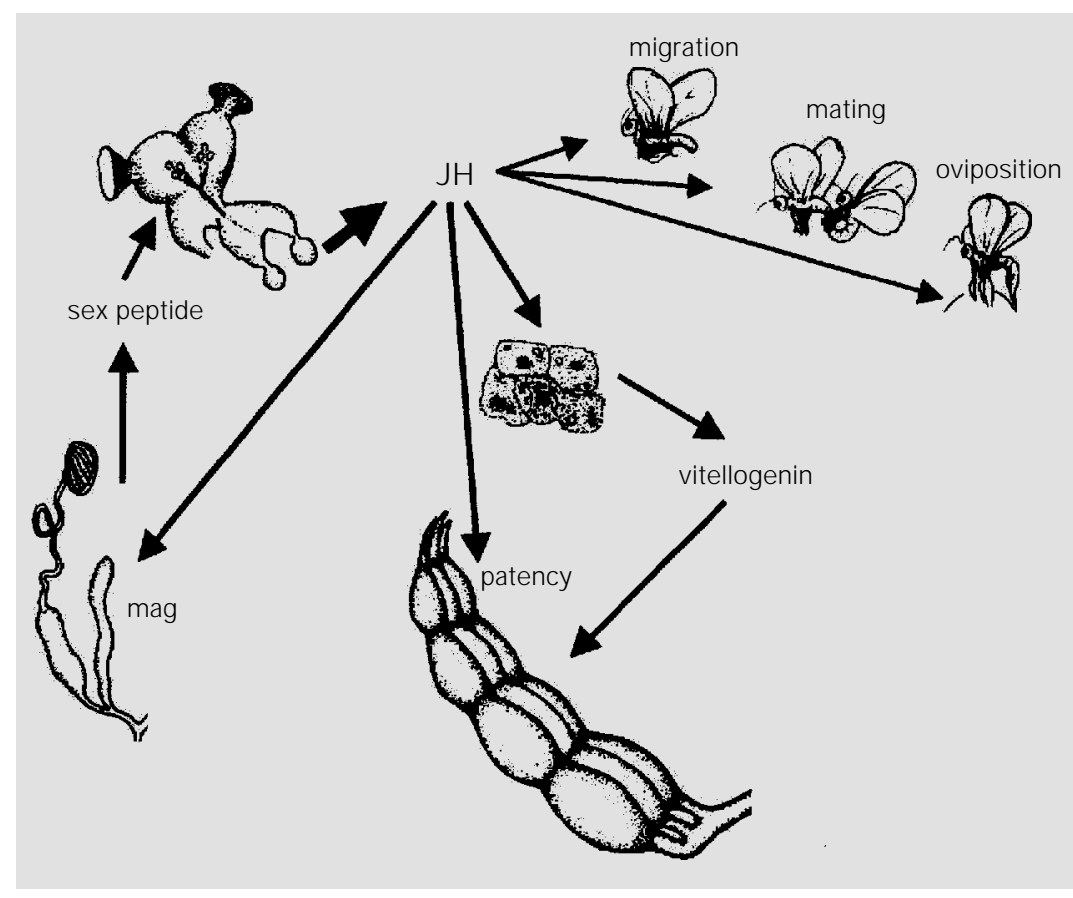

Figure 2 - Schematic representation of the principal functions of juvenile hormone $(\mathrm{H})$ in reproduction of adult insects. J H released by the corpora allata (CA) modulates behavior associated with dispersal and female reproduction. In the female fat body, J H stimulates vitellogenin synthesis, and in the ovary it facilitates vitellogenin uptake by increasing patency of the follicular epithelium. In males, JH stimulates protein synthesis in the male accessory glands (mag). In some species, a sex peptide produced by these glands is transmitted to the female during mating. This peptide subsequently acts on the CA and modifies postcopulatory behavior in the females and stimulates oogenesis. Obviously, many of these aspects are species-specific and subject to considerable variation. 
the oogenesis cycles, and vitellogenin transcription could be selectively activated after application of $\mathrm{JH}$ analogs to chemically allatectomized (precocene-treated) locusts. The regulation of such gene expression is currently best understood for a low MW protein (JHP21) synthesized and secreted by the locust fat body in close coordination with the vitellogenin gene products $\mathrm{VgA}$ and $\mathrm{VgB}$. The upstream control region of $j h p 21$ has been shown to contain a palindromic 15nucleotide motif (27) which resembles a canonical element recognized by the ecdysone receptor.

Regulation of vitellogenin gene transcription is clearly one of the prominent roles exerted by $\mathrm{JH}$ in reproductive cycles of female insects, and in this context the mode of action can be expected to involve a nuclear receptor. The second and not less important role of $\mathrm{JH}$ in oogenesis, however, appears to rely on an entirely different mechanism. In most insects, vitellogenin circulating in the hemolymph reaches the oocyte surface by passing through large spaces that appear between follicular epithelial cells in competent follicles. In Rhodnius prolixus, enlargement of these intercellular spaces in a process termed patency is entirely dependent on $\mathrm{JH}$ and is the result of a reduction in volume of the follicular epithelium cells. In vitro studies of this process in follicular epithelium membranes of $R$. prolixus and photoaffinity labeling with $\mathrm{JH}$ analogs of such membrane preparations in L. migratoria (19) have provided evidence for a transmembrane $\mathrm{JH}$ receptor. Binding of $\mathrm{JH}$ to this putative transmembrane receptor results in protein kinase $\mathrm{C}$-mediated phosphorylation of a $100-\mathrm{kDa}$ protein which is thought to represent the $\alpha$-subunit of $\mathrm{Na}^{+} / \mathrm{K}^{+}$ ATPase.

But to what extent can these aspects of the gonadotropic role of JH be generalized? The early and convincing results on the central role of JH in the control of female reproductive cycles in dictyopterans, hemipterans and orthopterans established the JH paradigm in insect reproduction, but also clearly impaired the interpretation of negative evidence obtained in other insect species and orders. In the autogenous mosquito Aedes aegypti, induction of vitellogenin synthesis in the fat body requires $20 \mathrm{E}$ (28), which is synthesized by the ovary in response to a blood meal-dependent release of ovarian ecdysteroidogenic hormone $(\mathrm{OEH}$, also termed EDNH) from the brain (29). In addition to ecdysteroids, which regulate fat body activity in mosquito reproduction, $\mathrm{JH}$ also plays an important but different role in mosquito oogenesis by preparing resting stage follicles to become competent for vitellogenesis after a blood meal. Furthermore, JH primes the fat body of newly emerged female mosquitoes to respond to $20 \mathrm{E}$. This priming function of $\mathrm{JH}$ in mosquitoes is similar to the one observed in newly emerged locusts and cockroaches, where it also confers competence on the fat body to respond with vitellogenin synthesis at full blast to subsequent peaks of the JH titer. A minimal model suggests that $\mathrm{JH}$ acts on the fat body of adult insects in two steps, requiring induction of one or more transcription factors which then induce enhanced transcription of vitellogenin genes (30).

\section{Male reproduction and effects of male sex peptides on female reproduction}

In contrast to the well established and complex role of $\mathrm{JH}$ in female reproductive physiology, there is little evidence for a significant role of $\mathrm{JH}$ in spermatogenesis. In many insect species, spermatogenesis initiates well before adult eclosion and may continue throughout adult life. It thus appears to occur equally well under quite different hormonal milieus, and only in a few species JH has been reported to affect spermatogenesis duration or spermatogonial mitotic cycles. In contrast to the gonads, the accessory glands of the male reproductive 
tract of many insect species turned out to be targets for JH (4). Synthesis of specific proteins in the male accessory gland of the migratory grasshopper, Melanoplus sanguinipes, is highly JH sensitive. A highaffinity binding protein for $\mathrm{JH}$ has been identified from nuclear extracts of this gland, and levels of this JH-binding protein increase during sexual maturation in close correlation with general protein synthesis in the male accessory glands of this grasshopper (31).

The products of the male accessory glands are not merely physical constituents of spermatophores and seminal fluid, but some of their products turned out to have pronounced effects on female reproduction. Less than 1 picomol of a 36-amino acid peptide, a socalled "sex peptide" produced by the accessory gland of Drosophila melanogaster males, has been shown to elicit characteristic postmating behavior in females, i.e., loss of receptivity for males and induction of oviposition behavior (32). Interestingly, though not totally surprising in the context of regulatory circuits in female reproduction, the female CA turned out to be targets of this sex peptide after its transfer to the female genital tract during copulation. In vitro assays with CA dissected from Drosophila virgin females showed that femtomolar concentrations of synthetic sex peptide resulted in strongly enhanced rates of JH biosynthesis (33). Interestingly, the Drosophila sex peptide is not a speciesspecific bioactive compound, but exhibits activity beyond species and even genus level. Recently, the synthetic Drosophila peptide has been shown to stimulate JH synthesis and to depress pheromone production in the noctuid moth Helicoverpa armigera (34). Male influence on female reproductive behavior by sperm fluid substances that modulate $\mathrm{JH}$ synthesis is probably the most recently discovered facet of $\mathrm{JH}$ as an endocrine master regulator of female reproduction.

\section{JH pleiotropy in female reproductive behavior, migration, and reproductive diapause}

In its simplest and clearest form, the role of $\mathrm{JH}$ as a pleiotropic master regulator of female reproductive physiology and behavior is expressed in cockroaches, where vitellogenesis and cyclic maturation of oocytes is dependent on JH and occurs in coordination with sexual behavior. This has led to the proposal that $\mathrm{JH}$ is the common regulator of reproduction. Sexual behavior, however, is more variable than reproductive physiology, and doubts have been raised whether $\mathrm{JH}$ acts as a true regulator for all aspects of female sexual behavior, or whether, at least in some cases, it merely plays a permissive role. In Blattella germanica, production and release (calling) of sex pheromone by the females occurs in close correlation with an increase in $\mathrm{JH}$ synthesis (35). However, a further increase in CA activity, as was observed after transfer of male factors during copulation, curtailed calling behavior and sexual receptivity. Other aspects of reproduction in female cockroaches, such as changes in feeding activity in relation to gonocycle and faster sexual maturation of females kept under crowded conditions in comparison to solitary females, are less well understood. A role for the CA has been proposed for both these aspects (35) but signal transduction pathways for social effects and feeding stimuli have not been worked out definitively.

In response to environmental factors (e.g., pronounced seasonality especially in colder temperate climates, decline in habitat quality, etc.), elements such as migration or diapause are introduced into insect life cycles and, consequently, regulation of reproduction becomes more complex. These elements can be integrated with reproduction in a variety of ways. The observation that migratory flights in search for more suitable sites for reproduction are undertaken by sexually immature adults in many species has led to 
the proposal of an "oogenesis-flight syndrome", meaning that migration and reproduction should be mutually exclusive and could not occur at the same time. Even though this formula is probably oversimplifying and may not fit all systems it has a considerable heuristic value. Strong evidence for a role of $\mathrm{JH}$ as a master regulator for the oogenesismigration syndrome comes from studies on the true armyworm, Pseudaletia unipunctata, a noctuid moth which exhibits migratory behavior in Northern populations and is non-migratory in the South. Comparison of onset of female calling behavior, progress in oogenesis, and rates of $\mathrm{JH}$ biosynthesis by CA of females during the first days after emergence revealed a time shift for these two populations, with the non-migratory Southern population being more advanced (36). In this context, JH has been proposed to regulate the synthesis of a pheromonotropic brain factor (PBAN-like factor) in specific peptidergic neurons, but in this respect $P$. unipunctata appears to be a rather exceptional case. Studies on another noctuid moth, Agrotis ipsilon, have shown that JH does not modulate PBAN synthesis but rather stimulates its release from the CNS (37).

The hormonal regulation of diapause, which is a physiological and not a behavioral response to unfavorable environmental conditions, is much better understood (for review, see Ref. 38). According to the positioning of diapause in an insect's life cycle, $\mathrm{JH}$ acts as a regulator in two distinct phases, i.e., in the larva and the adult. High JH titers, in some cases in conjunction with low ecdysteroid titers, prevent the pupal molt. In adults, low $\mathrm{JH}$ titers prevent reproduction and may induce searching behavior for suitable overwintering sites. Low JH titers during diapause are maintained either by repression of CA activity or by elevated levels of JH esterase. Diapause in other developmental stages is generally under the control of ecdysteroids, or, as in bivoltine strains of the silkworm, Bombyx mori, is induced by a maternal peptide that is released from the subesophageal ganglion during oogenesis and blocks embryonic development after oviposition.

Timing and frequency of mating are important life history parameters which are controlled by the endocrine system and which are integrated with the above described oogenesis-migration/diapause syndrome. Compiling datasets on egg development, timing of mating, and on number of matings, i.e., whether a female mates only once (monandry) or several times (polyandry), Ramaswamy et al. (39) distinguished four different strategies in moths and butterflies. In the first group (exemplified by Bombyx mori, Lymantria dispar and some other large moths), egg development starts as early as the larval stages and is completed in early pupae. In these species, vitellogenesis is dependent on ecdysteroids. The adult females do not feed and have a very short life span; they mate only once immediately after emergence and oviposit. In the second group, which includes the pyralid moths, egg development and vitellogenesis are shifted towards the end of pupal development and are associated with declining ecdysteroid titers. With some exceptions, females of this group also do not feed as adults and are monandrous. In the third group, exemplified by the tobacco hornworm, $M$. sexta, oogenesis starts in the pupal phase but is not regulated by the metamorphosis-triggering ecdysteroid titer. Choriogenesis is completed only in the newly emerged adults and is dependent on $\mathrm{JH}$. Females copulate several times shortly after emergence and exhibit stimulation of oogenesis after each mating. In the fourth group, which includes papilionid butterflies and noctuid moths, egg development initiates in the adult phase and $\mathrm{JH}$ is necessary for vitellogenin synthesis in the fat body, vitellogenin uptake by the oocytes, and also for choriogenesis. As described above, in a number of these latter species, the adults are sexually immature when they initiate migra- 
tory flights, and reproductive activities such as pheromone synthesis, calling, and oocyte maturation are closely linked and are $\mathrm{JH}$ dependent. Most of these species are polyandrous, and every additional mating results in further stimulation of egg production.

\section{Juvenile hormone and developmental polymorphism}

Upholding the option to migrate or to reproduce right away clearly implies costs for building and maintaining a flight apparatus, and natural selection should act to reduce the cost of such flight-reproductive trade-offs. Strong support for a fitness tradeoff between flight capability and reproduction is provided by comparative studies across a wide range of wing-polymorphic insects (40). Primary evidence for such a trade-off comes from a strong negative correlation between flight-muscle mass and ovarian mass, a relationship which suggests that construction and maintenance of the insect flight apparatus competes with egg production for a limited general pool of available nutrients. Various environmental cues such as crowding, host plant condition, temperature, and photoperiod have an influence on wing form. Wing dimorphism is well exemplified in gryllids and is even more pronounced in aphids. It is only in these two groups that questions of hormonal control of wing polymorphism have been pursued persistently (41).

\section{Wing dimorphism in crickets}

Early proposals have suggested that $\mathrm{JH}$ might play a prominent role in such developmental polymorphisms, i.e., in the evolution of correlated traits of flight and reproductive potential, but obviously, such traits are determined in different phases of the insect life cycle. In most of the above discussion I addressed the role of $\mathrm{JH}$ in metamorphosis as rather distinct from its later role in female reproduction. The fact that it is a pleiotropic master regulator for both programs, however, makes it at the same time a prime candidate to act as an integrative element in the evolution of wing and consequent reproductive polymorphic systems. In the cricket Gryllus rubens, application of JH III to larvae destined to mature into long-winged insects resulted in the formation of brachypterous adults, corresponding to the higher $\mathrm{JH}$ titer in the last larval instars of the brachypterous as compared to the macropterous morph. Interestingly, it is not an enhanced rate of $\mathrm{JH}$ biosynthesis which maintains the elevated $\mathrm{JH}$ titer in brachypters but rather decreased rates of $\mathrm{JH}$ metabolism due to a lower activity of JH esterase (41). When elevated $\mathrm{JH}$ titers persist in the last larval instar they are thought to inhibit metamorphosis of the wing anlagen and development of flight muscles.

\section{Phase polymorphism in aphids}

The evolution of flight-reproductive trade-offs probably has reached its apex in the aphids where apterous/alate wing dimorphism can occur in combination with switches between parthenogenetic and sexual modes of reproduction, and also with seasonal oscillation between host plant species. The primary mode of aphid reproduction is viviparous parthenogenesis. This has led to an even further abbreviation of life cycles by telescoping generations within a female's ovary. Virginoparae (parthenogenetic females which give birth to parthenogenetic progeny) contain embryos in different developmental stages within their ovaries. In the ovaries of the furthest developed embryos, oogenesis has already initiated and a next generation is being produced. Thus, the problem of how environmental cues are translated into endocrine signals to switch between the different modes of reproduction becomes very complex (42). The small size of aphids has furthermore precluded many 
surgical experiments and has also hampered the determination of morphogenetic hormone titers. The most convincing evidence for a role of $\mathrm{JH}$ in morph determination has been obtained for photoperiod-mediated wing polymorphism in Aphis fabae where $\mathrm{JH}$ application during a critical phase sensitive to photoperiod strongly redirected development from the winged (alate) to the flightless (apterous) form. Numerous aphid species, however, are not apterized by $\mathrm{JH}$ application during critical phases of morph determination. Instead, products of neurosecretory cells of the brain have been suggested as potential candidates for inducing aphid wing polymorphism (42). The pest status of many aphids has promoted intense research on the effects of precocenes which act as cytotoxins in CA cells of many insect species. In aphids these compounds should have the advantage of destroying not only the CA of adult females but also of their nascent progeny telescoped within the ovaries. Screening the activity of different precocene compounds in the pea aphid, Aphis pisum, has shown that some compounds inhibit wing production, whereas others promote wing formation (43). Such equivocal results for just one species, together with equally diverse results on effects of application of $\mathrm{JH}$ or $\mathrm{JH}$ analogs obtained in other aphid species, indicate that $\mathrm{JH}$ is only one amongst several factors in the determination of aphid wing polymorphism.

\section{The overestimated role of $\mathrm{JH}$ in locust phase polymorphism}

Another characteristic developmental polymorphism related to migration and reproduction is the phase polymorphism of migratory locusts, Locusta migratoria and Schistocerca gregaria. Depending on population density and habitat quality, locusts appear in two forms, termed phases, with a continuous range of intermediates between the extreme phases. These morphs differ in behavior, coloration (solitary green versus gregarious brown), mor- phometric traits, metabolism related to mobilization of energy resources for flight activity, and fertility (for review, see Ref. 44). In the gregarious phase, females tend to produce fewer eggs than in solitary generations. The fact that the green coloration typical for the solitary form could be induced by CA implantation into nymphs kept under crowded conditions, and the demonstration that the $\mathrm{JH}$ titer and CA activity during critical phases of development were indeed higher in isolated than in crowded locusts (45) suggested that $\mathrm{JH}$ could, also in this case, control morph characteristics and their integration with reproduction. Numerous apparently contradictory results obtained during screening tests for $\mathrm{JH}$ analogs as locust control agents, however, showed that the green coloration, which is considered typical for solitary locusts, and its inducibility by $\mathrm{JH}$ was strongly dependent on humidity. Another coloration characteristic, the gregarious yellow color, also turned out to be inducible by $\mathrm{JH}$ treatment. JH thus appears to be capable of shifting coloration characteristics quite independently of phase (46), and it appears to do so in synergism with peptide hormones released from the corpora cardiaca.

Behavioral phase characteristics could also be steared into opposite directions by $\mathrm{JH}$ treatment. Typical solitary behavior, such as aggression towards conspecifics, was enhanced in JH-treated crowded locusts and aggregation behavior was notably reduced. However, the marching activity of crowded hoppers, a gregarious phase characteristic of immatures, was intensified by $\mathrm{JH}$ treatment. Also with respect to reproduction, JH had phase-independent effects. It increased fecundity in crowded adult females to levels typical for the solitary phase, but at the same time it also accelerated oocyte maturation, which is not a phase characteristic. Thus, $\mathrm{JH}$ clearly is not the master regulator of locust phase polymorphism. Rather, it seems to play the same roles typically observed in other insects as well. Firstly, cuticle coloration may be varied by the well-known effects 
of JH on uptake and incorporation of hemolymph insecticyanins during the molting cycle and by interference with the melanization program during preimaginal development(3). Secondly, JH may be stimulating oogenesis in general and vitellogenesis in particular in adult females. The shifts between solitary and gregarious phase characteristics, on the other hand, appear to depend on a variety of other factors (46), including corpora cardiaca peptides, which may or may not exhibit interaction with JH-regulated programs. Synergism and antagonism of such factors with JH-regulated programs and the timing of such interactions may well be one of the reasons why locusts exhibit a continuous phase polymorphism with shifts extending over generations.

\section{JH and high society: caste polymorphism and division of labor in social insects}

The ecological significance of social insects is reflected in their shear biomass in which they are represented in the most varied ecosystems, from boreal climates where single ant species often represent the largest share of the biomass of soil arthropods, to the Amazonian rain forest, where social insects (bees, wasp, ants and termites) can account for up to $30 \%$ of the entire animal biomass. The answer to why they occupy such a dominant position is thought to reside in their social mode of life. Insect societies have frequently been compared to vertebrate and especially human societies, and there may even be lots of parallels regarding ultimate reasons. The proximate mechanisms generating the systems of division of labor observed in social insects, however, are obviously completely different from those in vertebrates, and in this regard, social insects are insects. The haplodiploid genetic system of sex determination in the Hymenoptera (including wasps, bees, and ants), and high genetic relatedness combined with depend- ence on endosymbionts in termites are considered to constitute the driving forces of social evolution in these groups which resulted in complex division of labor based on caste polymorphism and elaborate communication systems.

Members of the worker caste(s) have more or less given up on reproduction and have developed special structures making them more efficient foragers and defenders of their colonies, whereas reproduction has become the monopoly of one or few individuals, generally referred to as queens. As such, the system of division of labor is primarily a decision about who is to reproduce and who is not, and ultimately this is reduced to the problem of developing a functional reproductive tract. In addition, the imaginal disks for wings degenerate in the late larval stages in ant workers, and in termites, wing development in the workers is either blocked or does not start. Development of the gonads and of the ducts of the reproductive system, as well as wing differentiation obviously are aspects of metamorphosis. The differentiation of polymorphic castes can thus be expected to be controlled by the endocrine system, which itself responds to external cues. Such external cues are differential feeding of the larvae and/or inhibitory signals released by the functional reproductives. With few exceptions, caste determination does not result from a genetic bias.

\section{The key role of $\mathrm{JH}$ in honey bee caste differentiation}

Much groundwork elucidating the prominent role of $\mathrm{JH}$ in caste differentiation has been laid in the laboratory of Lüscher in Bern working on different termite species (for review, see Ref. 47). Size of individuals and colonies, and facility of rearing and manipulating colonies, however, have now established the honey bee, Apis mellifera, as the most advanced model for caste development and social regulation of division of 
labor (for a recent review, see Ref. 23). Detailed analyses of JH titers during embryonic, larval and pupal development of queen and worker honey bees have revealed dramatic differences in the third to early fifth larval instars, concurrently with a switch in the feeding program for queen and worker larvae. While nurse workers continuously feed copious amounts of royal jelly to queen larvae, worker larvae are reared on a mixed diet (royal jelly diluted with pollen and nectar). It is not yet clear how this trophic information is processed, but it eventually results in high rates of $\mathrm{JH}$ synthesis by the CA of queen larvae and low rates of $\mathrm{JH}$ synthesis in workers. One of the possibilities is that information on food quality and quantity is transmitted via the stomatogastric nervous system of honey bee larvae (48) which directly connects to the retrocerebral endocrine system via a hypocerebral nerve tract. The fact that a) this pathway ends near serotonergic cells located in the proximity of the $\mathrm{CA}$, and $\mathrm{b}$ ) serotonin and octopamine stimulate CA activity in honey bee larvae makes this pathway a plausible route for transmission of a nutritional switch signal.

The mode of action of $\mathrm{JH}$ in honey bee caste differentiation is highly pleiotropic. In the developing ovaries, JH affects cell proliferation during a critical phase in the last larval instar, and coincidently inhibits induction of programmed cell death in germ cells and somatic cells in the developing female gonad (49). Slightly later in the fifth instar, JH appears to stimulate the prothoracic glands, resulting in an earlier increase in ecdysteroid titers in queen larvae. Ecdysteroids in turn direct the caste-specific program of protein synthesis in the larval ovaries.

\section{Honey bee reproduction: JH is not a regula- tor of reproductive physiology but of reproductive behavior}

The early recognized prominent integra- tive role of JH in the morphological differentiation of the queen and worker caste and the paradigm of $\mathrm{JH}$ as a regulator of female fertility in insects in general has strongly influenced the direction of research activities on reproduction and division of labor in social insects, and particularly in honey bees. The reproductive physiology of adult honey bee queens differs from that of workers in two important respects, the rate and amount of vitellogenin synthesis and the production of queen pheromone. At egg laying rates up to 2,000 eggs per day it is not surprising that vitellogenin synthesis is consistently high and that its titer represents more than $50 \%$ of the hemolymph proteins of adult queens. Vitellogenin titers in workers reach elevated levels (25-30\% of total hemolymph proteins) only during the nurse bee phase. Workers are thus principally capable of producing and laying eggs (haploid eggs giving rise to males) as well, but are repressed to do so in the presence of a dominant queen. The queen inhibits ovary activation and follicle development in workers by her pheromones (principally (E)-9-oxo-2-decenoic acid). Under queenless conditions and in the absence of young larvae, however, egg laying by workers can frequently be observed.

Indeed, $\mathrm{JH}$ plays only a very subtle role in the reproductive physiology of female honey bees, and it clearly does not stimulate vitellogenin synthesis. Rather it appears to serve as an integrative element in social behavior and colony function (for review, see Ref. 23). Elevated JH levels are associated with periods of flight activity in queens and workers, and also in drones (50), the only difference being that the flights of queens and drones occur early in adult life and are associated with mating activities, whereas flight activities in workers initiate much later and serve to collect nectar, pollen, and water. JH application or allatectomy affected the onset of flight activities, thus demonstrating a general requirement for $\mathrm{JH}$ in flight activities in all three honey bee morphs 
$(51,52)$. In the case of workers, the onset of flight activity for foraging is controlled by age and colony conditions, and stands within the context of division of labor and agedependent performance of different tasks (age polyethism).

\section{Division of labor in highly social insects: a new role for an old hormone}

Recent studies have shown that the transition from intranidal activities to foraging is accompanied by a significant increase in CA activity, and that this modulation of $\mathrm{CA}$ activity depends on the age structure of a colony, i.e., the frequency at which a young bee encounters older bees affects its CA activity (53). Modulation of CA activity appears to require full physical contact and the possibility for exchange of age-characteristic signals in such worker-worker encounters (54). This JH-mediated transition to foraging activity does not only involve behavioral changes, but rather has, once more, pleiotropic effects. It results in degeneration and functional changes in the larval food-producing hypopharyngeal glands, a decrease in vitellogenin synthesis, and in restructuring of the protocerebral mushroom bodies (reviewed in Ref. 23). These latter changes are a prime example of $\mathrm{JH}$-mediated neuronal plasticity occurring in concert with changes in behavior. The transition from a nurse bee to a forager, thus evidently involves structural changes as the bee expands its learning capacity (55). When foraging, a bee has to know the location of the hive, learn the location of the food source, and has to communicate the latter via an elaborate dance language.

Behavioral integration of a honey bee colony does not only depend on encounters of workers of different age cohorts, but also involves genetic predisposition to certain tasks (56) and the signal of presence of a functional queen. As mentioned above, the queen suppresses worker fertility via a queen pheromone, but this queen pheromone is also a relevant indicator that colony reproduction is running at full speed. In this sense, the repressor action of queen pheromone components on CA activity in young bees can be interpreted as a regulator of colony demography guaranteeing an adequate cohort of nurse bees in colony reproduction. This primer effect of queen pheromone on workers apparently delays their behavioral ontogeny without affecting typical behavioral responses of workers to queen pheromone, such as retinue formation (57). Interestingly, biogenic amines appear to play a transmitter role in this context. Octopamine stimulates JH biosynthesis (58) and serotonin injections reduce the vitellogenin titer in nurse bees (Simões ZLP, personal information). These results are in accordance with the general view that external and colony conditions affect the levels of biogenic amines in the CNS of honey bee workers, and that these levels, in turn, may adjust task performance of individual workers by modulating their $\mathrm{JH}$ titers.

\section{The changing roles of $\mathrm{JH}$ in socioevolution}

It is interesting to note that in this highly social context, as exemplified by behavioral integration in a honey bee colony, JH has acquired two new functions. Firstly, elevated $\mathrm{JH}$ titers have become associated with flight activity and $\mathrm{JH}$ has apparently lost its gonadotropic role. This represents a dissociation of the "oogenesis-flight syndrome" as described above. Secondly, JH has become a key element in social integration. I decided to describe the dissociation of $\mathrm{JH}$ from reproductive functions other than mating flights as a loss of function because in bumble bees and polistine wasps, JH still retains such a function. In contrast to the highly social species where reproductive dominance is by and large a matter of "chemical control", the hierarchies of reproductive dominance in colonies of primitively social species are 
strongly based on and established by aggressive behavioral interactions, especially oophagy.

In the subfamily Polistini, colonies are founded by single females which are soon joined by cofoundresses. Caste differences are virtually absent in the paper wasps (genus Polistes) of temperate climates. All females present in such incipient colonies are mated and capable of egg laying. A single female, however, will eventually become dominant and monopolize reproduction. She signals her status of dominance to subordinate females by antennal tapping, and whenever she encounters eggs laid by other females on the comb she removes them. At the endocrine level, this hierarchy is reflected by elevated $\mathrm{JH}$ titers in the dominant females, and by low titers and low CA activity in the subordinate females (for review, see Ref. 59). High JH titers in these wasps are associated with activated ovaries and progressing oogenesis, and ovariectomy often leads to a reduction in $\mathrm{JH}$ titer and dominance status. Colony organization in the subtropical and tropical subfamilies Ropalidini and Polybiini is more complex. Incipient morphological caste characteristics have been postulated for Ropalidia marginata. Hormonal control mechanisms, however, have not yet been investigated. The advanced social polybiines already exhibit a system of age polyethism in their large colonies. In Polybia occidentalis, this age polyethism could be accelerated by $\mathrm{JH}$ application with effects strongly reminiscent of JH effects in honey bees (60).

The interactions of $\mathrm{JH}$ titers, progressing follicle development, and reproductive dominance appear to have been extensively exploited in social evolution, as exemplified by the bumble bees. The colony cycle in these predominantly temperate climate species initiates with colony foundation by a single queen. Once the first brood is reared and workers emerge, these aid the queen in the next brood cycles until the queen starts to lay haploid eggs giving rise to males (switch point). Subsequently, queens are frequently challenged by workers over the production of unfertilized, male-producing eggs (competition point), and soon afterwards the colonies disintegrate. Thus, at the end of the colony cycle the dominant queen appears to lose her dominant status which she had previously maintained by dominant behavior and a pheromone, and some of the workers of an "elite" group become egg layers as well (for review, see Ref. 61). Egg laying and the establishment of dominance hierarchies are also observed under conditions of queen loss. Thus, in the bumble bees, oogenesis and egg laying have apparently become dissociated within the context of social organization. Follicle development initiates in ovaries of workers, both in the presence and absence of the queen, but in the presence of the queen and dominant workers, these follicles are resorbed in the subdominant workers. Follicle development in workers generally starts 5 days after emergence and may be observed during much of their life span, quite different from the narrow temporal window for egg development in honey bee workers. Late stages of follicle development, however, were mainly observed in bumble bee workers belonging to the "elite" group after the competition point of the colony cycle. Ovary activation was also observed in experimental groups of queenless workers which were put together before their respective colonies had reached the competition point (62).

$\mathrm{JH}$ enters as a key player at several points in the regulation of dominance and egg development in bumble bees. JH titers were found to be high in egg-laying queens, and these high levels are considered to be required for vitellogenesis $(61,63)$. Elevated $\mathrm{CA}$ activity and corresponding $\mathrm{JH}$ titers were also observed in queenless workers which exhibited significantly more advanced levels of oogenesis than queenright workers $(63,64)$. Ovariectomy, however, did not af- 
fect CA activity in dominant workers, indicating that the dominance status, which appears to be established by aggressive interactions with fellow workers and possibly also by the production of a dominance-indicating pheromone in these workers at the competition point of the colony cycle, can be dissociated from their egg-laying capacity (61). The existence of a worker-produced dominance pheromone was also hypothesized from analyses of $\mathrm{JH}$ synthesis in young workers introduced into queenless groups established from colonies before and after the competition point (64).

The role of $\mathrm{JH}$ in colony organization of the more primitively social bumble bees exhibits striking differences from the role it plays in the highly social honey bees: a) JH is associated with dominance and reproduction (vitellogenesis) in the former but not the latter, b) age polyethism and division of labor among workers is not affected by JH in bumble bees $(65)$, c) foraging workers in bumble bee colonies have lower $\mathrm{JH}$ titers than workers that perform tasks within the nest, and d) mating flight activity of virgin queens is not affected by $\mathrm{JH}$ in bumble bees (61). An interesting parallel for $\mathrm{JH}$ function in primitively and highly social bees, though, becomes apparent when JH titers during the larval stages of prospective queens and workers are compared. Even though bumble bees do not have morphologically but only physiologically differentiated castes, CA activity in penultimate-instar queen larvae of Bombus terrestris is much higher than that detected in prospective workers (66). These incipient differences in levels of hormone synthesis, however, appear to be suppressed again during the prepupal phase (67), and thus apparently do not permit the development of morphological caste differences.

From these observations we can propose a dichotomy for the role of $\mathrm{JH}$ in social organization of hymenopteran colonies. In the primitively social wasps and bumble bees, JH still exerts a gonadotropic function and, in addition, becomes associated with the dominance status of individual females. The dominance status evidently is still tightly connected with reproduction. In the highly social honey bees, and possibly also in the stingless bees and in highly social wasps, the fixation of morphological caste differences has liberated JH from these functions. Egg production by queens in such colonies reaches levels far beyond the capacities of a bumble bee queen and requires very high and constant levels of vitellogenin synthesis by the fat body. This eliminates the need for cyclic regulation of oogenesis by $\mathrm{JH}$, so that egg production can now also occur at low $\mathrm{JH}$ titers. Evidently, in at least some of the highly social Hymenoptera this "old" hormone has been coopted for a fundamentally new function, which can only become apparent in a highly social context, namely division of labor based on age polyethism. In this context, JH even affects the organization of elementary brain structures. In highly social insects, the originally gonadotropic function of $\mathrm{JH}$ has thus been transformed into an integrator of colony function (colony reproduction), whereas its metamorphic function has been preserved and even been expanded to generate polymorphic castes.

This metamorphic function of $\mathrm{JH}$ has reached its summit in the ants, where $\mathrm{JH}$ orchestrates not only the differentiation of the queen and worker castes, but also guides the formation of morphologically distinct worker morphs. This role of $\mathrm{JH}$ has been investigated in detail in the genus Pheidole where production of the strongly dimorphic soldiers and workers depends on differences in $\mathrm{JH}$ levels during the late larval stages, whereas the queen-worker decision is made much earlier in larval development (68). Developmental rules underlying the production of these secondary castes have been outlined as JH-mediated modulation of allometric growth parameters in the different imaginal discs (69). Only few ant species have been studied with regard to a putative 
gonadotropic role of $\mathrm{JH}$, and rather equivocal results were obtained. Whereas JH treatment stimulates shedding of the wings and oogenesis in newly emerged virgin queens of the fire ant, Solenopsis invicta (70), JH titers in reproductives of the ponerine ant Diacamma sp were consistently low (71). In Diacamma, JH titers were found to be positively correlated with worker age, suggesting a role for $\mathrm{JH}$ in division of labor, much like the picture emerging in the honey bee.

The evolution of insect polymorphisms, including the complex caste systems of social insects, has been reviewed under premises of phenotypic plasticity $(23,72)$. The driving forces towards sociality in the Hymenoptera appear to have been a) the haplodiploid system of sex determination generating asymmetries in the relatedness among offspring, and b) the tendency of females to return and reuse the parental nest. The subsequent chain of effects probably did not require genetic change. It included the formation of groups, establishment of reproductive dominance by aggressive interactions between nestmates, and care for larvae by non-ovipositing females. All these traits can be seen as derived from species that do not nest socially and are interpretable as behavioral trait amplification. Adaptive phenotypes could then have originated by minor genetic changes via correlated shifts in the expression of phenotypically plastic traits. The pleiotropic functions of $\mathrm{JH}$ in insect development and reproductive physiology in general made this hormone system an ideal integrator for caste development and social organization. During social evolution, the gonadotropic role of JH has apparently suffered a striking transformation from its original function in egg production and dominance rank to a behavioral pacemaker in division of labor among workers (70).

\section{Concluding remarks}

Methylfarnesoate derivatives made their appearance in arthropod evolution as "sup- porting actors" in the ecdysteroid-regulated molting process. In the larval and pupal stages of insect life cycles, $\mathrm{JH}$ is now known to modify the expression patterns of ecdysteroid-regulated genes, creating the possibility for an insect to express different types of cuticles, and in particular to develop from a larval form to an adult form through a complex metamorphosis. Complete metamorphosis, as observed in the holometabolous insects, is the key to the intraspecific separation of ecological niches occupied by larvae and adults, and undoubtedly has played a major role in the tremendous ecological and evolutionary radiation of holometabolous insects.

The multiple functions of $\mathrm{JH}$ during preimaginal development may have been a preadaptation for its implication in the regulation of reproductive processes, where the primary functions appear to have been the synchronization of vitellogenin synthesis by the fat body and vitellogenin uptake by developing oocytes during distinct reproductive cycles. Diversification of life and reproductive cycles, together with the necessity to avoid conditions unfavorable for reproduction, have added ever more facets to $\mathrm{JH}$ function. One of the most intriguing new facets is the recent discovery that sex peptides produced by the male accessory glands cause a complex behavioral switch in mated females, from mate-seeking to mate-rejection and oviposition behavior. A synthetic Drosophila sex peptide has now been shown to modulate $\mathrm{JH}$ biosynthesis levels in the $\mathrm{CA}$ of different insect species.

Life cycle complexity in insects is further increased in species exhibiting facultative polymorphism, such as wing dimorphism in crickets, phase polymorphism in desert locusts and aphids, and the castes of social insects. In social evolution, $\mathrm{JH}$ seems to have first been implicated in the coupling of oogenesis to status in a dominance hierarchy. This is a reflection of the early steps of socioevolution where colonies are established 
by the joining of sisters or unrelated females. All of these females are mated and thus can function as potential egg layers, but in general one of these will effectively monopolize reproduction and suppress oviposition by the others, mainly by antagonistic behavior. In these primitively social insects, high $\mathrm{JH}$ titers generally exhibit a high correlation with dominance status and follicle development in the ovaries. In the populous colonies of highly social insects, one or more reproductively dominant females reign by means of pheromones. These elicit behavioral responses in the workers, guaranteeing colony cohesion and suppressing follicle development in the ovaries of workers. $\mathrm{JH}$ is involved in several aspects of the life cycle in such highly social species, and its multiple roles are currently best understood in the honey bee. First of all, JH titers exhibit castespecific modulation during critical developmental periods in the larval instars. These titer differences eventually lead to the expression of different (alternative) develop- mental programs in the ovaries and in other target tissues. JH has thus gained a key function in the generation of polymorphic castes. Secondly, $\mathrm{JH}$ has lost its association with oogenesis, and thus, could be coopted into other functions in adult bees. It now coordinates mating flight activities in newly emerged queens and drones, and serves as a behavioral pacemaker in workers. This latter function represents a new and fascinating facet in JH pleiotropy which allows to integrate colony demography and colony needs with the age-related performance of specific tasks by each individual worker bee.

\section{Acknowledgments}

I would like to thank Zilá Luz Paulino Simões (USP, Ribeirão Preto), Anna Rachinsky (Kansas State University, Manhattan) and Isabel Boleli (UNESP, Jaboticabal) for comments on a previous version of this manuscript and for sharing with me unpublished results.

\section{References}

1. Biggers WJ \& Laufer H (1996). Detection of juvenile hormone-active compounds by larvae of the marine annelid Capitella sp. Archives of Insect Biochemistry and Physiology, 32: 475-484.

2. Homola E \& Chang ES (1997). Methyl farnesoate: Crustacean juvenile hormone in search of functions. Comparative Biochemistry and Physiology. B, Biochemistry and Molecular Biology, 117: 347-356.

3. Riddiford LM (1994). Cellular and molecular actions of juvenile hormone. I. General considerations and premetamorphic actions. Advances in Insect Physiology, 24: 213-274.

4. Wyatt GR \& Davey KG (1996). Cellular and molecular actions of juvenile hormone. II. Roles of juvenile hormone in adult insects. Advances in Insect Physiology, 26: 1-155.

5. Darrouzet E, Mauchamp B, Prestwich GD, Kerhoas L, Ujvary I \& Couillaud F (1997). Hydroxy juvenile hormones: New putative juvenile hormones biosynthesized by locust corpora allata in vitro. Biochemical and Biophysical Research Communica- tions, 240: 752-758.

6. Tobe SS \& Stay B (1985). Structure and regulation of the corpus allatum. Advances in Insect Physiology, 18: 305-432.

7. Tobe SS \& Pratt GE (1974). The influence of substrate concentrations on the rate of juvenile hormone biosynthesis by corpora allata of the desert locust in vitro. Biochemical J ournal, 144: 107-113.

8. Stay B, Fairbairn S \& Yu CG (1996). Role of allatostatins in the regulation of juvenile hormone synthesis. Archives of Insect Biochemistry and Physiology, 32: 287-297.

9. Kataoka H, Toschi A, Li J P, Carney RL, Schooley DL \& Kramer S (1989). Identification of an allatotropin from adult Manduca sexta. Science, 243: 1481-1483.

10. Rachinsky A \& Tobe SS (1996). Role of second messengers in the regulation of juvenile hormone production in insects, with particular emphasis on calcium and phosphoinositide signaling. Archives of Insect Biochemistry and Physiology, 33: 259-282.
11. Sutherland TD \& Feyereisen R (1996). Target of cockroach allatostatin in the pathway of juvenile hormone biosynthesis. Molecular and Cellular Endocrinology, 120: 115-123.

12. Wang $Z W$, Ding Q, Yagi KJ \& Tobe SS (1994). Terminal stages in juvenile hormone biosynthesis in corpora allata of Diploptera punctata - Developmental changes in enzyme activity and regulation by allatostatins. J ournal of Insect Physiology, 40: 217-223.

13. Thompson CS, Yagi KJ , Chen ZF \& Tobe SS (1990). The effects of octopamine on juvenile hormone biosynthesis, electrophysiology, and CAMP content of the corpora allata of the cockroach Diploptera punctata. J ournal of Comparative Physiology. B, Biochemical Systemic and Environmental Physiology, 160: 241-249.

14. Rachinsky A (1994). Octopamine and serotonin influence on corpora allata activity in honey bee (Apis mellifera) larvae. J ournal of Insect Physiology, 40: 549-554.

15. Goodman WG (1990). Biosynthesis, titer 
regulation, and transport of juvenile hormones. In: Gupta AP (Editor), Morphogenetic Hormones of Arthropods. Vol. 1. Rutgers University Press, New Brunswick, 83-124.

16. deKort CAD \& Granger NA (1996). Regulation of J $\mathrm{H}$ titers: The relevance of degradative enzymes and binding proteins. Archives of Insect Biochemistry and Physiology, 33: 1-26.

17. Prestwich GD, Wojtasek H, Lentz AJ \& Rabinovich J M (1996). Biochemistry of proteins that bind juvenile hormones. Archives of Insect Biochemistry and Physiology, 32: 407-419.

18. Wyatt GR (1997). J uvenile hormone in insect reproduction - a paradox? European J ournal of Entomology, 94: 323-333.

19. Sevala VL, Davey KG \& Prestwich GD (1995). Photoaffinity labeling and characterization of a juvenile hormone binding protein in the membranes of follicle cells of Locusta migratoria. Insect Biochemistry and Molecular Biology, 25: 267-273.

20. Ashok M, Turner C \& Wilson TG (1998). Insect juvenile hormone resistance gene homology with the bHLH-PAS family of transcriptional regulators. Proceedings of the National Academy of Sciences, USA, 95: 2761-2766.

21. Restifo LL \& Wilson TG (1998). A juvenile hormone agonist reveals distinct developmental pathways mediated by ecdysoneinducible Broad Complex transcription factors. Developmental Genetics, 22: 141159.

22. Gruetzmacher MC, Gilbert LI, Granger NA, Goodman W \& Bollenbacher WE (1984). The effect of juvenile hormone on prothoracic gland function during the larval-pupal development of Manduca sexta: An in situ and in vitro analysis. J ournal of Insect Physiology, 30: 331-340.

23. Hartfelder K \& Engels W (1998). Social insect polymorphism: Hormonal regulation of plasticity in development and reproduction in the honeybee. Current Topics in Developmental Biology, 40: 45-77.

24. Zhou BH, Hiruma $K$, J indra $M$, Shinoda $T$, Segraves WA, Malone $F \&$ Riddiford LM (1998). Regulation of the transcription factor $\mathrm{E} 75$ by 20-hydroxyecdysone and juvenile hormone in the epidermis of the tobacco hornworm, Manduca sexta, during larval molting and metamorphosis. Developmental Biology, 193: 127-138.

25. J ones G, Schelling D \& Chokar V (1996). Overview of the regulation of metamorphosis-associated genes in Trichoplusia ni. Archives of Insect Biochemistry and Physiology, 32: 429-437.
26. Hagedorn $\mathrm{HH}$, Maddison $\mathrm{DR} \& \mathrm{Tu} \mathrm{Z}$ (1998). The evolution of vitellogenins, cyclorrhaphan yolk proteins and related molecules. Advances in Insect Physiology, 27: 335-384.

27. Zhang J Z, Saleh DS \& Wyatt GR (1996). $J$ uvenile hormone regulation of an insect gene: A specific transcription factor and a DNA response element. Molecular and Cellular Endocrinology, 122: 15-20.

28. Hagedorn HH, O'Connor J D, Fuchs MS, Sage B, Schlaeger DA \& Bohm MK (1975). The ovary as a source of $\alpha$-ecdysone in an adult mosquito. Proceedings of the National Academy of Sciences, USA, 72: 3255-3259.

29. Klowden MJ (1997). Endocrine control of mosquito reproduction. Archives of Insect Biochemistry and Physiology, 35: 491512.

30. Wyatt GR, Braun RP \& Zhang J (1996). Priming effect on gene activation by juvenile hormone in locust fat body. Archives of Insect Biochemistry and Physiology, 32: 633-640.

31. Ismail SM \& Gillot C (1996). Identification of a nuclear juvenile hormone-binding protein in the long hyaline tube of male Melanoplus sanguinipes. Archives of Insect Biochemistry and Physiology, 32: 623631.

32. Schmidt $T$, Choffat $Y$, Klauser $\mathrm{S} \&$ Kubli E (1993). The Drosophila melanogaster sex peptide - a molecular analysis of structure-function relationships. J ournal of Insect Physiology, 39: 361-368.

33. Moshitzky P, Fleischmann I, Chaimov N, Saudan P, Klauser S, Kubli E \& Applebaum SW (1996). Sex peptide activates juvenile hormone biosynthesis in Drosophila melanogaster corpus allatum. Archives of Insect Biochemistry and Physiology, 32: 363-374.

34. Fan YL, Rafaeli A, Gileadi C, Kubli E \& Applebaum SW (1999). Drosophila melanogaster sex peptide stimulates juvenile hormone synthesis and depresses sex pheromone production in Helicoverpa armigera. J ournal of Insect Physiology, 45: 127-133.

35. Schal C, Holbrook GL, Bahmann J AS \& Sevala VL (1997). Reproductive biology of the German cockroach, Blatella germanica: J uvenile hormone as a pleiotropic master regulator. Archives of Insect Biochemistry and Physiology, 35: 405-426.

36. MCNeil J N, Laforge $M$, Bédard $C \&$ Cusson M (1996). J uvenile hormone production and sexual maturation in true armyworm, Pseudaletia unipunctata (HAW.) (Lepidoptera: Noctuidea): A comparison of migratory and non-migratory populations. Archives of Insect Biochemistry and Physiology, 32: 575-584.

37. Picimbon J F, Becard J M, Sreng L, Clement J L \& Gadenne C (1995). J uvenile hormone stimulates pheromonotropic brain factor release in the female black cutworm, Agrotis ipsilon. J ournal of Insect Physiology, 41: 377-382.

38. Denlinger DL (1985). Hormonal control of diapause. In: Kerkut GA \& Gilbert LI (Editors), Comprehensive Insect Physiology, Biochemistry and Pharmacology. Vol. 8. Pergamon Press, Oxford, 353-412.

39. Ramaswamy SB, Shu S, Park YI \& Zeng F (1997). Dynamics of juvenile hormonemediated gonadotropism in the Lepidoptera. Archives of Insect Biochemistry and Physiology, 35: 539-558.

40. Roff DA (1986). The evolution of wing dimorphism in insects. Evolution, 40: 3037.

41. Zera AJ \& Denno RF (1997). Physiology and ecology of dispersal polymorphism in insects. Annual Review of Entomology, 42: 207-231.

42. Hardie J \& Lees AD (1985). Endocrine control of polymorphism and polyphenism. In: Kerkut GA \& Gilbert LI (Editors), Comprehensive Insect Physiology, Biochemistry and Pharmacology. Vol. 8. Pergamon Press, Oxford, 441-490.

43. Hardie J, Gao N, Timár T, Sebök $P$ \& Honda K-I (1996). Precocene derivatives and aphid morphogenesis. Archives of Insect Biochemistry and Physiology, 32: 493-501.

44. Pener MP (1991). Locust phase polymorphism and its endocrine relations. Advances in Insect Physiology, 23: 1-79.

45. Injeyan HS \& Tobe SS (1981). Phase polymorphism in Schistocerca gregaria: assessment of juvenile hormone synthesis in relation to vitellogenesis. J ournal of Insect Physiology, 27: 203-210.

46. Pener MP \& Yerushalmi $Y$ (1998). The physiology of locust phase polymorphism: An update. J ournal of Insect Physiology, 44: 365-377.

47. Noirot C \& Bordereau C (1991). Termite polymorphism and morphogenetic hormones. In: Gupta AP (Editor), Morphogenetic Hormones of Arthropods. Vol. 3. Rutgers University Press, New Brunswick, 295-324.

48. Boleli IC, Simoes ZLP \& Hartfelder K (1998). The stomatogastric nervous system of the honey bee (Apis mellifera) in a critical phase of caste development. J ournal of Morphology, 236: 139-149.

49. Schmidt Capella IC \& Hartfelder K (1998) 
J uvenile hormone effect on DNA synthesis and apoptosis in caste-specific differentiation of the lanval honey bee (Apis mellifera L.) ovary. J ournal of Insect Physiology, 44: 385-391.

50. Robinson GE, Strambi C, Strambi A \& Feldlaufer MF (1991). Comparison of juvenile hormone and ecdysteroid hemolymph titers in adult worker and queen honey bees (Apis mellifera). J ournal of Insect Physiology, 37: 929-935.

51. Giray T \& Robinson GE (1996). Common endocrine and genetic mechanisms of behavioral development in male and worker honey bees and the evolution of division of labor. Proceedings of the $\mathrm{Na}$ tional Academy of Sciences, USA, 93: 11718-11722.

52. Tozetto SO, Rachinsky A \& Engels W (1997). J uvenile hormone promotes flight activity in drones (Apis mellifera carnica). Apidologie, 28: 77-84.

53. Huang ZY \& Robinson GE (1992). Honeybee colony integration - worker-worker interactions mediate hormonally regulated plasticity in division of labor. Proceedings of the National Academy of Sciences, USA, 89: 11726-11729.

54. Huang ZY, Plettner E \& Robinson GE (1998). Effects of social environment and worker mandibular glands on endocrinemediated behavioral development in honey bees. J ournal of Comparative Physiology. A, Sensory Neural and Behavioral Physiology, 183: 143-152.

55. Fahrbach SE (1997). Regulation of age polyethism in bees and wasps by juvenile hormone. Advances in the Study of Behavior, 26: 285-316.

56. Page RE \& Robinson GE (1991). The genetics of division of labor in honey bee colonies. Advances in Insect Physiology, 23: 117-169.
57. Pankiw $T$, Huang $Z Y$, Winston $M L \&$ Robinson GE (1998). Queen mandibular gland pheromone influences worker honey bee (Apis mellifera L.) foraging ontogeny and juvenile hormone titers. J ournal of Insect Physiology, 44: 685-692.

58. Kaatz H-H, Eichmüller S \& KreissI S (1994). Stimulatory effect of octopamine on juvenile hormone biosynthesis in honey bees (Apis mellifera): Physiological and immunocytochemical evidence. J ournal of Insect Physiology, 40: 865-872.

59. Strambi A (1990). Physiology and reproduction in social wasps. In: Engels W (Editor), Social Insects - an Evolutionary Approach to Castes and Reproduction. Springer, Berlin, 59-75.

60. O'Donnell S \& J eanne RL (1993). Methoprene accelerates age polyethism in workers of a social wasp (Polybia occidentalis). Physiological Entomology, 18: 189-194.

61. Röseler P-F \& van Honk CGJ (1990). Castes and reproduction in bumblebees. In: Engels W (Editor), Social Insects - an Evolutionary Approach to Castes and Reproduction. Springer, Berlin, 147-166.

62. Bloch G \& Hefetz A (1999). Regulation of reproduction by dominant workers in bumblebee (Bombus terrestris) queenright colonies. Behavioral Ecology and Sociobiology, 45: 125-135.

63. Bloch $G$, Borst DW, Huang $Z Y$, Robinson GE, Cnaani J \& Hefetz A (2000). J uvenile hormone titers, juvenile hormone biosynthesis, ovarian development and social environment in Bombus terrestris. J ournal of Insect Physiology, 46: 47-57.

64. Bloch $G$, Borst DW, Huang $Z Y$, Robinson GE \& Hefetz A (1996). Effects of social conditions on juvenile hormone mediated reproductive development in Bombus terrestris workers. Physiological Entomol- ogy, 21: 257-267.

65. Cameron SA \& Robinson GE (1990). J uvenile hormone does not affect division of labor in bumble bee colonies. Annals of the Entomological Society of America, 83: 626-631.

66. Cnaani J, Borst DW, Huang ZY, Robinson GE \& Hefetz A (1997). Caste determination in Bombus terrestris: Differences in development and rates of $\mathrm{J} \mathrm{H}$ biosynthesis between queen and worker larvae. J ournal of Insect Physiology, 43: 373-381.

67. Strambi A, Strambi C, Röseler P-F \& Röseler I (1984). Simultaneous determination of juvenile hormone and ecdysteroid titers in the hemolymph of bumblebee prepupae (Bombus hypnorum and B. terrestris). General and Comparative Endocrinology, 55: 83-88.

68. Wheeler DE \& Nijhout HF (1983). Soldier determination in the ant, Pheidole bicarinata: Hormonal control of caste and size within castes. J ournal of Insect Physiology, 29: 847-854.

69. Nijhout HF \& Wheeler DE (1996). Growth models of complex allometries in holometabolous insects. American Naturalist, 148: 40-56.

70. Robinson GE \& Vargo EL (1997). J uvenile hormone in adult eusocial Hymenoptera: Gonadotropin and behavioral pacemaker. Archives of Insect Biochemistry and Physiology, 35: 559-583.

71. Sommer K, Hölldobler B \& Rembold H (1993). Behavioral and physiological aspects of reproductive control in a Diacamma species from Malaysia (Formicidae, Ponerinae). Ethology, 94: 162-170.

72. West-Eberhard MJ (1989). Phenotypic plasticity and the origins of diversity. Annual Review of Ecology and Systematics, 20: 249-278. 